ethics. This range means that the collection can be read in two main ways. First, it can be read simply for factual information. In this respect, perhaps unsurprisingly, it is the contributions that are predominantly medicine-based and law-based that are generally the most useful.

Secondly, the book can be read for clarification of the ethical issues surrounding reproductive technology. Here, the reader is immediately confronted by a catholicity of the concepts of ethics. For example, ethics refers sometimes to what appears on the agenda of a hospital ethics committee (in Richard West's contribution), to a specific moral or religious stance which is commended to practitioners (in the contributions of Richard Lilford and Jack Mahoney), and sometimes to a branch of academic philosophy (in Anne Fagot-Largeault's contribution).

This catholicity does of course represent the wide range of opinion in medical ethics, but in a single collection it inevitably poses a problem. Despite the convenient grouping of the book according to substantive topics, the sheer range of approaches makes it difficult for the reader to identify the precise points at which different contributors would agree or disagree. The discussions go part of the way towards such an identification, but, like most conference discussions, they reveal a fair amount of mutual misunderstanding between contributors. It is probably for these reasons that the most successful part of the book is where withholding neonatal care is examined first by Alexander Campbell as a paediatrician and, in response, by Jennifer Jackson as a philosopher. Here, and in the usefully delimited discussion that follows, genuine debate is discernible, taking the level of analysis beyond that of mere juxtaposition of diverse views.

ELIZABETH KINGDOM Department of Sociology, Social Policy and Social Work Studies, University of

Liverpool.

\section{Protecting the vulnerable: autonomy and consent in health \\ care}

Edited by Margaret Brazier and Mary Lobjoit, 183 pages $+\mathrm{xi}$, London, 1991. Routledge, $£ 30.00$
This volume in the 'Social ethics and policy' series is a collection of papers, some of which were originally given as part of a public lecture series in Manchester in 1988. The unifying theme is the ethical and legal problems of making health-care decisions in cases where patients are, or at least are thought to be, partially or completely incapable of making valid decisions for themselves. This unity at one level of course conceals enormous variety at another, since the forms which such actual or apparent incompetence can take are incredibly varied, as are the decisions which have to be taken in providing care for such patients. The ethical problems generated are equally varied. Thus the papers range over very premature babies, people with mental handicap, women undergoing sterilisation, subjects of non-therapeutic research, people with suicidal tendencies and those receiving psychotherapy, especially students. In addition to the discussions of particular types of decision, there are also more theoretical papers about the nature of autonomy, informed consent and the right to information.

The papers on particular types of case are on the whole sensible, practical and sensitive, but hardly groundbreaking. The policy recommendations made are usually plainly right but there often seems to be a reluctance really to get to grips with the ethical complexities of a situation. For instance, Heather Draper, writing about the sterilisation of mentally handicapped women, recommends a review of the law concerning wardship and research into the attitudes of mentally disabled women towards pregnancy, labour and children - both eminently sensible suggestions. But the ethical issue in such cases - the balance to be drawn between the interests of the woman herself, those of the people who care for her and those of the potential child - is referred to but never really explored in her paper, and she comes to the conclusion that sterilisations must be 'solely in the interests of the individual concerned'.

An exception to this line of criticism is Gavin Fairbairn's paper 'Suicide and justified paternalism'. Drawing both on his reflections on his own professional experience and on a subtle philosophical analysis, Fairbairn succeeds in moving beyond the tired discussions of the right to suicide and gives an account of the ethics of preventing suicide which makes due allowance for the interests of those other than the suicider who are involved. In the course of this, he also has interesting general things to say about, for instance, paternalism: much, he says, of what passes for paternalism is really 'self-interested pseudo-paternalism because it is more concerned with protecting its perpetrator than with caring for the welfare of the individual in question'.

The more theoretical papers are variable in quality. Margaret Brazier very thoroughly examines the legal problems of treating incompetent patients, but rightly concludes that the rights of, for example, mentally handicapped people depend far more on general social attitudes to disabled people than on legal frameworks. Richard Lindley's paper on a doctor's duty to inform patients of the facts in cases of surgery comes to interesting conclusions, recommending a form of the Bolam test which takes in groups other than medical experts. Harry Lesser provides a useful discussion of the patient's right to information. Alastair Campbell's paper, however, seems simply confused. He makes great play with the notion that patients are dependent on their doctors, as they clearly are, but seems to think that that implies limits to the value of patient autonomy rather than being precisely the reason why respect for patient autonomy is needed.

ERIC MATTHEWS Department of Philosophy, University of Aberdeen.

\section{Organ replacement therapy: ethics, justice, commerce}

First joint meeting of ESOT

(European Society for Organ

Transplantation) and

EDTA/ERA(European Renal

Association) in Munich, 11-14

December, 1990. Edited by W Land and J B Dossetor, 578 pages + xxiii, London and Berlin, 1991. SpringerVerlag, £78.50

The contents pages of this volume list 81 papers, five transcripts of plenary discussion sessions, and 201 contributors, giving some idea as to the huge input the conference it is based upon received. The articles range in kind from those which are more or less purely medical, though having 